\title{
Modelamento termal de uma auréola metamórfica em torno de uma intrusão básica hipabissal paleógena na Bacia Potiguar, Nordeste do Brasil
}

\author{
Thermal modeling of a metamorphic aureole around a paleogene \\ hypabissal basic intrusion within the Potiguar Basin, Northeast of Brazil
}

\author{
Samir do Nascimento Valcácio ${ }^{1}$, Zorano Sérgio de Souza, ${ }^{1,2}$, \\ José Antônio de Morais Moreira ${ }^{3}$, Juliana Garrido Damaceno ${ }^{1}$ \\ ${ }_{1}^{1}$ Programa de Pós-Graduação em Geodinâmica e Geofísica, Universidade Federal do Rio Grande do Norte - UFRN, \\ Avenida Senador Salgado Filho, 3.000, Caixa Postal 1.596, Bairro Lagoa Nova, CEP 59078-970, Natal, RN, BR \\ (samirvalcacio@hotmail.com; jurrido@hotmail.com) \\ 2Departamento de Geologia, Universidade Federal do Rio Grande do Norte - UFRN, Natal, RN, BR (zorano@geologia.ufrn.br) \\ ${ }^{3}$ Departamento de Geofísica, Universidade Federal do Rio Grande do Norte - UFRN, Natal, RN, BR (moreira@geofisica.ufrn.br)
}

Recebido em 05 de janeiro de 2016; aceito em 20 de março de 2017

\begin{abstract}
Resumo
A Bacia Potiguar possui um volume considerável de rochas básicas alcalinas. Os efeitos térmicos associados a essas rochas em bacias sedimentares podem ocasionar um tipo peculiar de metamorfismo de contato, o pirometamorfismo, capaz de fundir parcialmente as rochas encaixantes e gerar novas rochas. Este trabalho reporta o efeito térmico dessas intrusões cenozoicas, conhecidas como Magmatismo Macau, em rochas cretáceas da Bacia Potiguar, com auxílio de dados de campo, petrografia e petrofísica. Para isso, foi simulado o arrefecimento térmico por meio de modelos matemáticos no entorno do plug São João, localizado a nordeste de Pedro Avelino (estado do Rio Grande do Norte, Nordeste do Brasil), correlacionando-o a mudanças mineralógicas identificadas nas rochas encaixantes. As modificações físicas e texturais mais expressivas na evolução de altas para baixas temperaturas são a fusão parcial e recristalização das rochas encaixantes, compactação e fraturamento hidráulico. O modelamento térmico indica que a auréola metamórfica pode atingir até $150 \mathrm{~m}$ do contato. Além disso, as associações minerais relacionadas ao metamorfismo de contato (cordierita, tridimita e espurrita, além de vidro) permitem estimar condições de temperaturas mínimas da ordem de $1.000{ }^{\circ} \mathrm{C}$ e pressões de 0,5 kbar. O modelamento térmico sugere que as mudanças mineralógicas e texturais foram efetivas com temperaturas a partir de $400{ }^{\circ} \mathrm{C}$. O tempo de resfriamento estimado para o plug São João é de aproximadamente 10 mil anos. Tais dados são relevantes para entender o efeito do magmatismo na remobilização de hidrocarbonetos e sua influência nos sistemas petrolíferos da Bacia Potiguar.
\end{abstract}

Palavras-chave: Pirometamorfismo; Petrofísica; Bacia Potiguar; Nordeste do Brasil.

\begin{abstract}
The Potiguar Basin encompasses a considerable volume of alkaline basic rocks. The thermal effects associated with the emplacement of igneous rocks on sedimentary sequences can cause a peculiar type of contact metamorphism, the pyrometamorphism, which produces partial melting of host rocks and generate new rocks. This paper discusses the thermal effects caused by Cenozoic intrusions, known as Macau Magmatism, over Cretaceous rocks of the Potiguar Basin by means of field, petrographic and petrophysical data. Using mathematical models, the thermal cooling was simulated in the proximity of the São João plug, northeastern of Pedro Avelino village (state of Rio Grande do Norte, NE, Brazil). The results were correlated with mineralogical changes in the surrounding rocks. The most significant physical and textural changes from high to low temperatures are partial melting and recrystallization, compression and hydraulic fracturing. The thermal modeling indicates that the metamorphic aureole can reach up to $150 \mathrm{~m}$ from the contact. In addition, mineral assemblages related to contact metamorphism (cordierite, tridymite, spurrite, besides glass) allow to estimate minimum temperature conditions of the order of $1,000{ }^{\circ} \mathrm{C}$ and pressure of $0.5 \mathrm{kbar}$. Thermal modeling suggests that mineralogical and textural changes were effective for temperatures above $400{ }^{\circ} \mathrm{C}$. The estimate for the São João plug cooling time is about 10,000 years. These data are relevant in order to understand the effect of magmatism on the remobilization of hydrocarbons and its influence on the Potiguar Basin petroliferous systems.
\end{abstract}

Keywords: Pyrometamorphism; Petrophysics; Potiguar Basin; NE Brazil. 


\section{INTRODUÇÃO}

A ocorrência de corpos intrusivos ígneos em bacias sedimentares contendo óleo e/ou gás preenche uma condição relevante para aspectos exploratórios e econômicos. O calor advindo de tais intrusões propicia a maturação da matéria orgânica presente nas rochas-fontes, diminui a densidade do óleo e aumenta a velocidade de migração de hidrocarbonetos para rochas-reservatório (Ujié, 1986; Chen et al., 1999; Thomaz Filho et al., 2008; Wang et al., 2012). Em contrapartida, o mesmo calor pode diminuir a quantidade de óleo armazenado, gerando mais gás, e minimizar a permeabilidade e a porosidade de rochas-reservatório em decorrência da recristalização de alguns minerais, podendo até destruir completamente a matéria orgânica do reservatório original (Thomaz Filho et al., 2008; Eiras e Wanderley Filho, 2003).

$\mathrm{Na}$ Bacia Potiguar, há várias ocorrências de rochas afetadas termalmente por pirometamorfismo em torno de intrusões básicas hipabissais (Paiva, 2004; Silveira, 2006; Sousa, 2009; Santos, 2011, 2013; Nobre, 2012). Essas intrusões básicas alojadas em baixa profundidade $(<3 \mathrm{kbar})$ propiciam condições de altíssimas temperaturas $\left(\sim 1.150^{\circ} \mathrm{C}\right)$ nas unidades encaixantes em proximidade, podendo atingir fácies sanidinito. Nessa situação, algumas litologias podem sofrer fusão parcial e gerar rochas do tipo buchito ou propiciar a transformação extensiva de calcário em mármore. No caso da área em questão, rochas siliciclásticas e pelíticas da Formação Açu e carbonáticas da Formação Jandaíra foram particularmente afetadas (Souza et al., 2012; Santos et al., 2014; Terra, 2015; Terra et al., 2016).
Este estudo teve como objetivo a caracterização geológica detalhada do entorno de uma intrusão cenozoica aflorante na Bacia Potiguar e, ainda, a simulação da dissipação de calor por condução relacionada a processos pirometamórficos que afetaram rochas encaixantes.

Para atingir os objetivos mencionados no parágrafo anterior, foram realizadas as seguintes atividades:

- levantamento em campo de relações de contato das intrusões e encaixantes sedimentares;

- análise de imagens de sensores remotos orbitais;

- aquisição de dados petrográficos e texturais a partir de 36 lâminas delgadas (microscópio óptico Leica DMLP Programa de Pós-Graduação em Geodinâmica e Geofísica da Universidade Federal do Rio Grande do Norte PPGG/UFRN); e

- obtenção de dados petrofísicos por meio de medições da condutividade e difusividade térmica de 12 amostras selecionadas no campo (diabásios, arenitos, buchitos, calcários e mármores), tendo sido usado o equipamento Quickline-30 Thermal Properties Analyzer (Laboratório de Propriedades Físicas das Rochas - PPGG/UFRN).

\section{CONTEXTO GEOLÓGICO DOS CORPOS ESTUDADOS}

A área de estudo situa-se na Bacia Potiguar, cuja localização está centrada na porção extremo leste da margem equatorial brasileira (Figura 1). A bacia está inserida nos estados do Rio Grande do Norte e Ceará, totalizando cerca de $48.000 \mathrm{~km}^{2}$

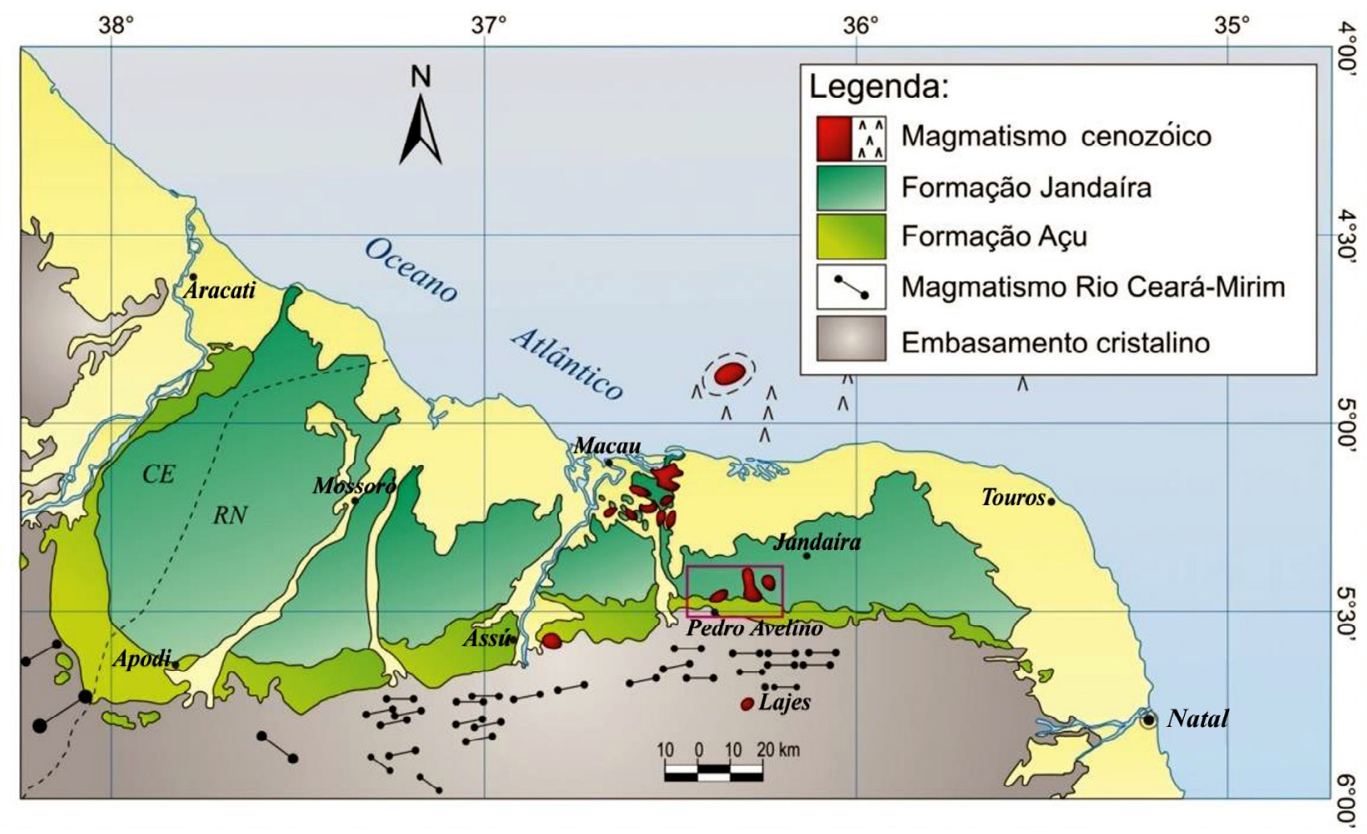

Figura 1. Mapa geológico simplificado da porção emersa da Bacia Potiguar (modificado de Cassab, 2003; Angelim et al., 2006). A área objeto deste trabalho está delimitada pelo retângulo vermelho. 
de área, dos quais 55\% encontram-se na parte oceânica e $45 \%$ na porção emersa (Pessoa Neto et al., 2007).

De acordo com Chang et al. (1988) e Matos (1992, 2000), a origem da Bacia Potiguar está ligada a três estágios tectônicos, denominados sin-rifte I, II e III. Para Matos (1992), seu arcabouço estratigráfico pode ser agrupado em quatro sequências deposicionais: rifte, transicional, drifte transgressiva e drifte progradacional. Em publicações mais recentes, Pessoa Neto et al. (2007) relacionam esse arcabouço a três supersequências: rifte, pós-rifte e drifte.

A formação da Bacia Potiguar, segundo Pessoa Neto et al. (2007), teve início no período Neoberriasiano/ Eobarremiano, no qual, sob regime tectônico rúptil distensivo, foram depositados sedimentos fandeltaicos, flúviodeltaicos e lacustres pertencentes às formações Pendência e Pescada. O período seguinte (Neoaptiano) correspondeu ao início de uma subsidência térmica, propiciando a deposição de sedimentos flúvio-lacustres e os primeiros registros de incursão marinha (Formação Alagamar). A partir do Albiano, predominou um regime tectônico marcado por subsidência térmica e deriva continental, com a sedimentação associada a uma sequência flúvio-marinha transgressiva, que corresponde às formações Açu, Ponta do Mel, Quebradas e Jandaíra. Por fim, do período Neocampaniano até o Holoceno, o registro estratigráfico foi marcado por sequências de ciclo regressivo caracterizado por sistemas de talude/bacia, sistemas de plataforma rasa com borda carbonática e mistos compostos por leques costeiros.
Os correspondentes dessas sequências são definidos pelas formações Ubarana, Guamaré, Tibau e Barreiras.

De acordo com Souza et al. (2003, 2007, 2013) e Knesel et al. (2011), os principais eventos magmáticos conhecidos são identificados na Bacia Potiguar como magmatismo Rio Ceará-Mirim (131,0 \pm 1,0 Ma), Serra do Cuó $(93,1 \pm 0,8 \mathrm{Ma})$ e Macau (70,0 a 6,0 Ma). O magmatismo Rio Ceará-Mirim constitui um feixe isolado de diques de diabásio, com orientação sublatitudinal (preferencialmente $\mathrm{E}-\mathrm{W}$ ) de natureza basáltica toleítica. O magmatismo Serra do Cuó, constituído por derrames e plugs, possui a mesma natureza; e o Macau difere dos anteriores por se tratar de basaltos e diabásio alcalinos (Araújo et al., 2001; Mizusaki et al., 2002; Souza et al., 2003; Knesel et al., 2011).

A partir de imagens de satélite, radar, fotografias aéreas e expedições de campo, foi possível definir a dimensão, geometria, texturas e zonas de metamorfismo de contato em regiões de intrusões ígneas básicas referentes ao Magmatismo Macau na Bacia Potiguar. Os principais dados petrofísicos foram coletados no entorno do plug São João, localizado a cerca de $13 \mathrm{~km}$ de Pedro Avelino (RN). Na região, dois corpos podem ser identificados. O corpo principal, representado na Figura 2, tem forma aproximadamente circular com cerca de $800 \mathrm{~m}$ de diâmetro. O segundo corpo aflora a cerca de $100 \mathrm{~m}$ do limite leste da área da Figura 2; ele tem forma elíptica alongada na direção NW-SE, medindo aproximadamente $700 \mathrm{~m}$ (NW-SE) por $300 \mathrm{~m}$ (SW-NE). Em função de acessibilidade, apenas o corpo de maior diâmetro foi estudado neste trabalho.

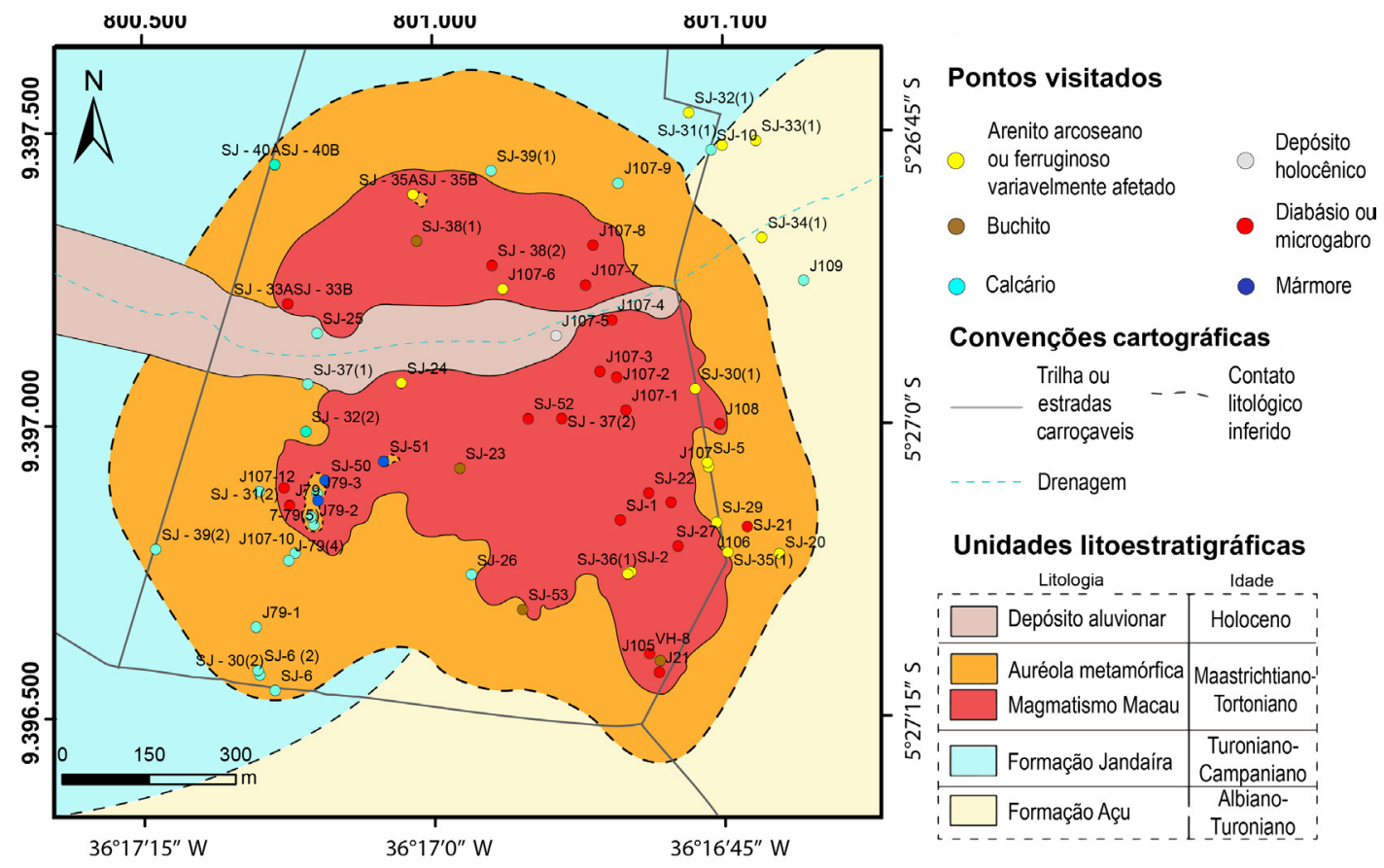

Figura 2. Mapa geológico mostrando a localização dos corpos na região do plug São João, alvo deste trabalho. Interpretações baseadas em dados de campo e fotografias aéreas (Santos et al., 2014; Vital et al., 2011). 
O plug São João está encaixado em arenitos e calcários das formações Açu e Jandaíra, respectivamente. No seu entorno, as rochas são afetadas em graus distintos. Quanto mais próximas das intrusões, há aumento gradativo de granulação, compactação e ausência e/ou obliteração de fósseis (no caso dos calcários). O maior registro do efeito térmico é notificado pela presença de xenólitos de mármore, zonas de silicificação e buchitos no corpo ígneo (Figura 3A). Os possíveis protólitos dessas rochas seriam, respectivamente, calcários e arenitos.

Os calcários e arenitos no entorno do plug São João podem ser encontrados como blocos soltos em meio a solos esbranquiçados derivados dessas rochas, que se distinguem do solo massapê formado pela alteração do corpo ígneo (Figura 3B).

\section{CARACTERIZAÇÃO PETROGRÁFICA E PETROFÍSICA}

\section{Corpo básico intrusivo}

O plug São João apresenta granulação média a grossa na parte central (diabásios e microgabros), passando a fina (diabásio fino ou basaltos) na borda. Em geral, são rochas macroscopicamente holocristalinas, faneríticas, destacandose por vezes ripas de plagioclásio numa matriz granular. Localmente, ocorrem venulações de espessura milimétrica a centimétrica de basalto cortando microgabro (Figura 4A). Xenólitos de calcário, mármore, buchitos e arenitos se concentram em suas porções SW e E.

Foram descritas nove seções delgadas do plug. A mineralogia observada compreende plagioclásio, piroxênio (série augita - Ti-Augita), olivina e minerais opacos. Calcedônia e calcita podem ocorrer preenchendo amígdalas (Figura 4B), assim como serpentina e acículas de apatita
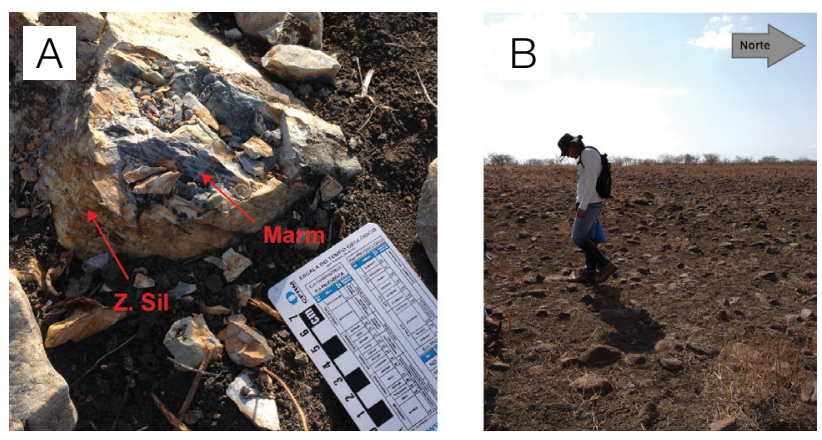

Marm: mármore; Z. Sil: zona de silicificação associada.

Figura 3. (A) Aspecto macroscópico do mármore com zona de silicificação associada; (B) porção central do plug São João com solo escuro derivado de processos intempéricos em rochas básicas (basaltos e diabásios). Afloramentos SJ-32 e SJ-37, respectivamente. como minerais de alteração. Vidro vulcânico e matriz são observados em alguns casos. De acordo com os critérios de classificação de Streckeisen (1976), esse grupo de amostras foi classificado como augita diabásio.

A olivina é incolor de hábito anédrico. Alguns cristais apresentam extinção ondulante e bordas corroídas. O processo de alteração principal ocorre por serpentinização a partir de fraturas ou bordas do mineral, e o tamanho dos cristais pode atingir de 3 a $5 \mathrm{~mm}$ em diabásios. Propriedades óticas (incolor, biaxial positivo e ângulo $2 \mathrm{~V} \sim 80^{\circ}$ ) sugerem tratar-se da olivina do tipo forsterita.

O clinopiroxênio ocorre como cristais incolores, castanho-claros, subédricos prismáticos e anédricos. Pode apresentar zonação interna com maior concentração de titânio na borda, indicada pela coloração acastanhada mais acentuada, e, por vezes, ocorre como aglomerados com textura esquelética e glomeroporfirítica. O tamanho dos cristais pode variar entre 0,3 e $5,0 \mathrm{~mm}$, com propriedades óticas (coloração acastanhada, pleocroismo fraco, ângulo $2 \mathrm{~V} \sim 60^{\circ}$, ângulo de extinção $40^{\circ}$ e elongação positiva) indicando tratar-se de um piroxênio da série augita - Ti-augita.

O plagioclásio ocorre de forma ripiforme a tabular. Em regiões próximas às bordas dos corpos há textura do tipo traquitoide relacionada ao fluxo magmático. Já na porção mais central, as ripas aparentemente não apresentam orientação preferencial. Os fenocristais podem alcançar $2 \mathrm{~mm}$ em diabásios e 3,5 $\mathrm{mm}$ em microgabros; são subédricos a anédricos, podendo ocorrer como inclusões parciais em clinopiroxênio. Os teores de anortita foram estimados de acordo com o método de MichelLevy em $\mathrm{An}_{30-40}$.

Minerais opacos ocorrem de forma subédrica a anédrica, geralmente associados ao clinopiroxênio e dispersos na matriz, com até $0,25 \mathrm{~mm}$ de tamanho. A apatita é incolor, encontrada em forma acicular com até $0,2 \mathrm{~mm}$. Por fim, a calcedônia e a calcita podem preencher amígdalas.
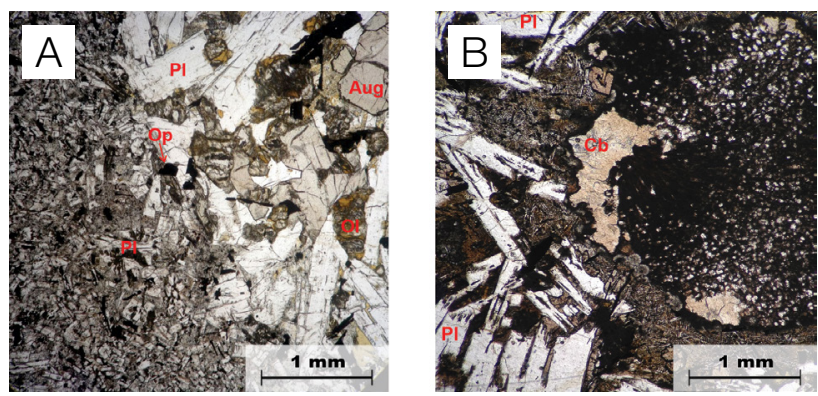

Pl: plagioclásio; Op: minerais opacos; Aug: augita; Ol: olivina; Cb: carbonato. Figura 4. Microtexturas do plug básico em nicóis paralelos. (A) contato de venulação de basalto (à esquerda) com microgabro, onde se destaca a textura subofítica com augita intergranular; (B) ripas de plagioclásio (à esquerda) e amígdala com preenchimento parcial de calcita. Amostras J107.8 e J107.3, respectivamente. 


\section{Rochas encaixantes}

Os arenitos da Formação Açu termicamente não afetados pelas intrusões são compostos por quartzo mono e policristalino com extinção ondulante, intraclastos argilosos, $\mathrm{K}$-feldspato e minerais opacos. O cimento ocorre como uma massa oxidada (Figura 5A) na porção $\mathrm{E}$ do corpo, ou como calcedônia na porção $\mathrm{N}$ e em xenólitos no plug (Figura 5B).

Para melhor detecção de transformações dentro da auréola pirometamórfica foram utilizados parâmetros para os arenitos tais como: granulometria, grau de seleção, tipo de contatos, empacotamento, maturidade textural e mineralógica, compilados de diversos autores (Wentworth, 1922; Kahn, 1956; Pettijohn et al., 1972; Schmidt e Mcdonald, 1979; Pettijohn et al., 1987).

A granulometria dos arenitos varia de areia grossa a fina (1 a $0,125 \mathrm{~mm}$ ) com moderado grau de seleção (grau de seleção $=1$, de Pettijohn et al., 1972). Seu arredondamento e sua esfericidade são, respectivamente, subarredondado a subangular e baixa (de acordo com classificação de Power, 1953 apud Pettijohn et al., 1987). Os contatos são predominantemente flutuantes, comumente pontuais e retos e raramente côncavo-convexos, seguindo parâmetros de Scholle, 1979. O empacotamento é frouxo (índice de empacotamento $=35$, de Kahn, 1956) e sua maturidade textural e mineralógica é matura e alta, respectivamente.

De acordo com a classificação de Folk (1968), a rocha varia entre um quartzo arenito e um arenito subarcoseano. Os efeitos termais ligados a regiões próximas à intrusão $(<15$ $\mathrm{m}$ do contato) relacionam-se ao ligeiro acréscimo no índice de empacotamento nos arenitos (passando para $\mathrm{p}=40$ ) e, em locais muito próximos, com menos de $5 \mathrm{~m}$ do contato, nota-se a fusão parcial da rocha. Neles, formam-se vidro e cordierita em buchitos escuros. De acordo com Grapes (2011), esses elementos e tipo de rocha podem ser usados
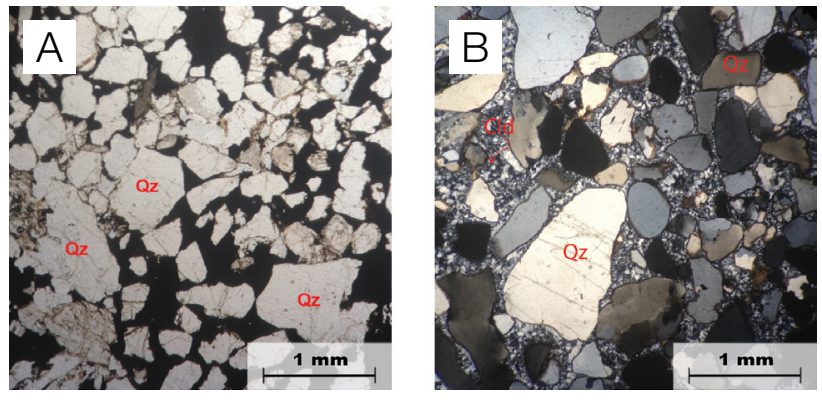

Qz: quartzo. Cld: calcedônia

Figura 5. Aspectos petrográficos gerais de arenitos encaixantes preservados. (A) fotomicrografia de arenitos subarcoseanos com grãos subangulosos de quartzo e cimento ferruginoso (em nicóis paralelos); (B) arenito subarcoseano com grãos sub-arredondados a arredondados e cimento formado por calcedônia (com polarizadores cruzados). Amostras SJ-40A e SJ-38, respectivamente. como marcadores de pressão-temperatura, ocorrendo no intervalo de 950 a $1.000^{\circ} \mathrm{C}$ e em pressões menores que 0,5 kbar (Figura 6).

Além de apresentarem menor porcentagem de vidro que os buchitos escuros (Figura 7A), os buchitos claros do plug São João não desenvolvem minerais indicadores com granulação acessível a microscópio petrográfico (Figura 7B). Todavia, no corpo de Nova Conquista (Assentamento Nova Conquista - ANC), região próxima verificada em campo, agulhas de tridimita chegam a $0,3 \mathrm{~mm}$ (Figuras $7 \mathrm{C}$ e 7D), marcando pelo menos $850^{\circ} \mathrm{C}$.

As amostras mais representativas de rochas carbonáticas encaixantes contêm bioclastos e intraclastos em matriz micrítica ou esparítica formada por dolomita ou calcita espática, sendo classificadas como grainstone e packstone, segundo Dunham (1962), ou biointraesparito e micrito (Figuras 8A e 8B), de acordo com Folk (1959). Os principais bioclastos encontrados são foraminíferos, espinhos de equinoderma, algas e fragmentos de bivalves. Também foram observados calcários contendo essencialmente micrito ou esparito com porosidade móldica preenchida por romboedros de dolomita, classificados como mudstone (Dunham, 1962) ou micritos e esparitos (Folk, 1959).

Observaram-se nas rochas porosidades dos tipos interpartícula, intrapartícula, intercristalina, móldica e vugs. Além disso, podem ser encontrados sedimentos terrígenos siliciclásticos associados a regiões proximais do contato com arenitos da Formação Açu, geralmente compostos por quartzo e feldspato. Também notaram-se birdseye, geodos de calcita, ilmenita e possível matéria orgânica.

Os calcários afetados pelo pirometamorfismo ocorrem em até $150 \mathrm{~m}$ do contato. Algumas das características térmicas evidentes nessas rochas são a redução gradual de sua porosidade e o aparecimento de porções recristalizadas e/ou de maior cristalinidade no micrito, quanto mais perto do corpo intrusivo (Figura 9A). Em regiões próximas, por volta de 10 a $15 \mathrm{~m}$ do contato, encontram-se rochas bastante fraturadas, desprovidas de fósseis e preenchidas com calcita espática (Figura 9B). Além disso, foram verificados mármores com blastos centimétricos de calcita e dolomita (Figura 9C).

\section{Petrofísica das rochas}

O ensaio de condutividade e difusividade térmica foi realizado por meio do aparelho Quickline-30 Thermal properties analyzer em condição de temperatura controlada e constante $\left(21^{\circ} \mathrm{C}\right)$. Para isso, confeccionaram-se as amostras em formato tabular de dimensão $10 \times 10 \times 3 \mathrm{~cm}^{3}$, o que proporcionou 5 análises em locais distintos na amostra (Figura 10). As medições aconteceram em seus vértices, em sentido anti-horário, e, em seguida, houve uma medição no centro. Algumas amostras foram submetidas a dois ensaios para testar e avaliar as variações e os erros do equipamento para um 


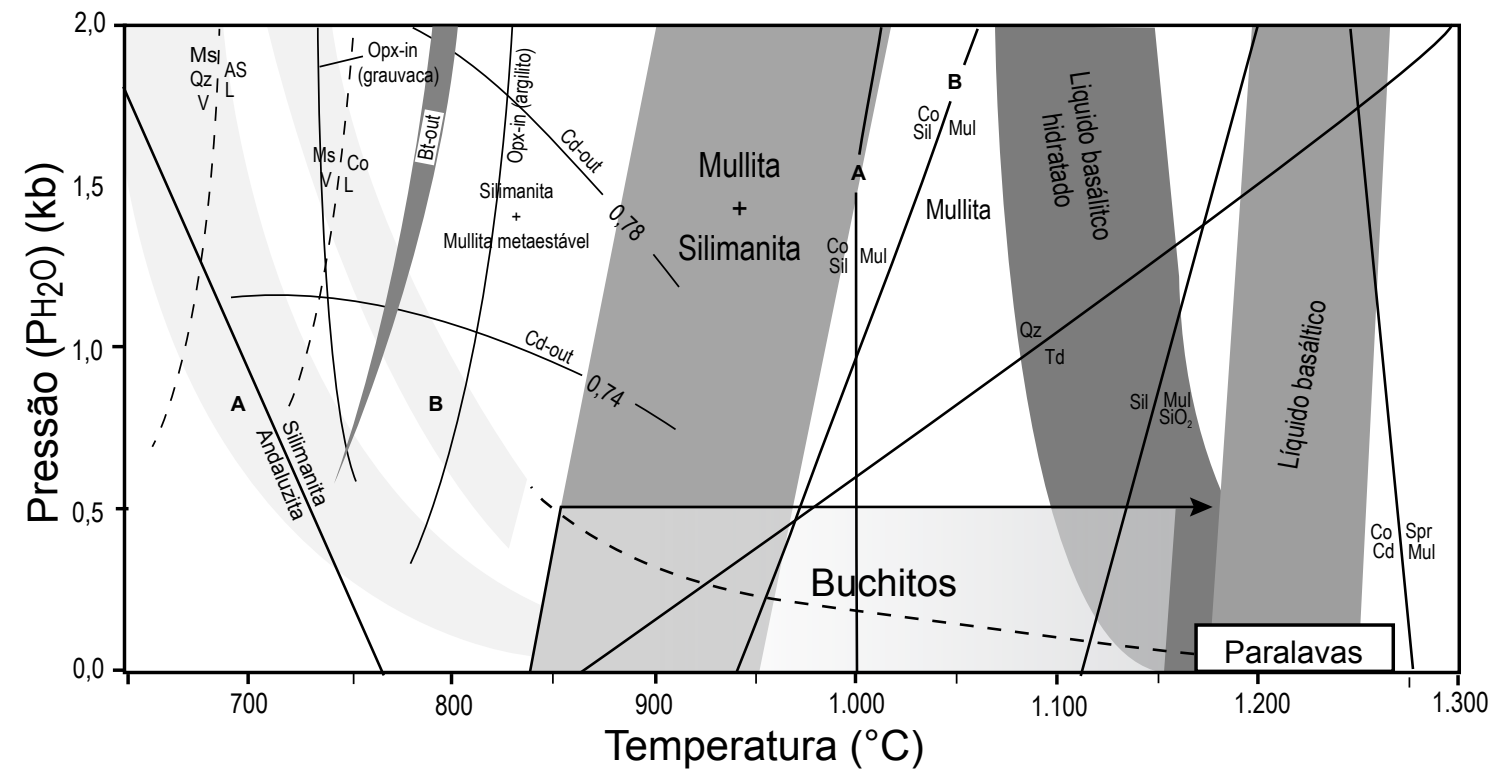

Figura 6. Diagrama P-T para rochas de composição quartzo-feldspática termalmente afetadas e assembleias minerais típicas associadas (compilado de Grapes, 2011).
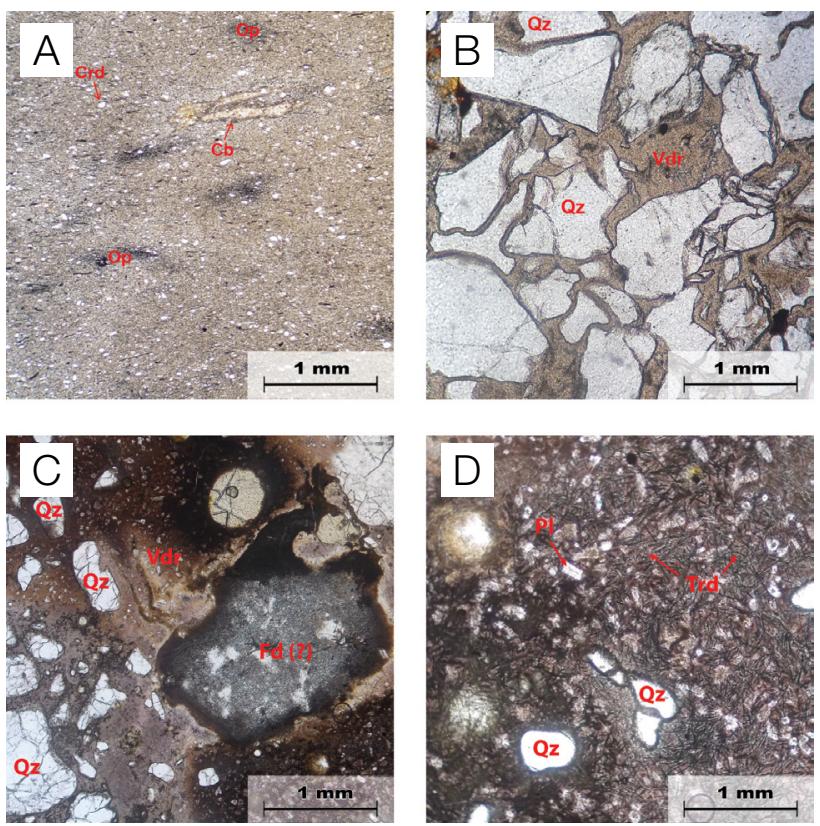

Crd: cordierita; Op: minerais opacos; Cb: carbonato; Qz: quartzo; Vdr: material vitreo; Fd: feldspato; Pl: plagioclásio; Trd: tridimita.

Figura 7. Minerais e microtexturas em arenitos encaixantes. (A) aspecto geral de um buchito claro, com surgimento de material vítreo (em polarizadores paralelos); (B) aspecto do buchito escuro, com destaque para o material vítreo castanho englobando material carbonático e formação de grânulos de cordierita (em nicóis paralelos); (C) possível assimilação de feldspato em vidro gerado pelo processo de fusão parcial dos arenitos (em polarizadores paralelos); (D) desenvolvimento de cristais aciculares de tridimita (em polarizadores paralelos). Amostras SJ-23, SJ-35, ANC-1C e ANC-1C, respectivamente.
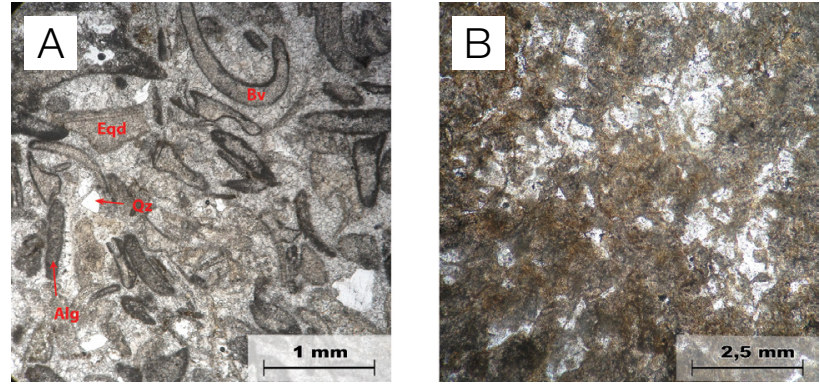

Bv: bivalves; Eqd: equinodermas; Qz: quartzo; Alg: algas.

Figura 8. Componentes observados em rochas carbonáticas não afetadas termalmente. (A) biointraesparito com grande quantidade de bioclastos (algas, equinodermas e bivalves) na amostra SJ-5; (B) aspecto geral de um micrito na amostra SJ-35B. Fotomicrografias tiradas com polarizadores paralelos.

mesmo ponto verificado. Esse teste averiguou variações da ordem de centésimos, previstas de acordo com as especificações do aparelho usado.

Para o entendimento das relações entre as características petrográficas e petrofísicas, consideraram-se fatores como: composição modal, fraturas (preenchidas ou não) e tamanho dos grãos, além das variações devidas aos efeitos metamórficos e por alterações tardias.

Amostras de rochas vulcânicas e hipabissais não mostram grandes variações quanto à condutividade térmica $(\lambda)$, que revelam valores entre 1,81 e 1,84 W/mK. O baixo valor pode ser explicado pela grande quantidade de plagioclásio nessas rochas, que, segundo Horai (1971), possui valores de $\lambda$ por volta de $2,00 \mathrm{~W} / \mathrm{mK}$. Além disso, os minerais de maior 
condutividade térmica nelas (em torno de 4,50 a $5,00 \mathrm{~W} / \mathrm{mK}$ ) são piroxênios e olivinas, e representam pouco mais do que um quarto da porcentagem (Figura 11).

Calcários e mármores apresentam condutividade entre $2,70 \mathrm{~W} / \mathrm{mK}$ e $3,59 \mathrm{~W} / \mathrm{mK}$, o que pode ser explicado pelas mudanças físicas e mineralógicas associadas ao efeito térmico.

Em relação à mineralogia, a condutividade térmica nas amostras estudadas é regida essencialmente pelas condutividades da calcita $(3,570 \mathrm{~W} / \mathrm{mK})$ e da dolomita $(5,500 \mathrm{~W} / \mathrm{mK}) \mathrm{e}$ pela porosidade, uma vez que, quando os poros estão preenchidos por ar, atinge valores em torno de $0,024 \mathrm{~W} / \mathrm{mK}$, reduzindo bastante a condutividade da rocha (Horai, 1971).

Logo, é de se esperar que a condutividade aumente proporcionalmente à compactação da rocha, diminuindo os espaços porosos de baixa condutividade até que a porosidade seja nula. Porém, a recristalização e a remobilização de calcita - de condutividade baixa em relação à dolomita - em fraturas nas porções dolomitizadas fazem com que os valores de condutividade diminuam com a proximidade da intrusão.

Assim, quando se traça um perfil de condutividade das regiões menos afetadas para as mais afetadas, os valores encontrados apresentam aleatoriedade compreendida no intervalo mencionado. Portanto, para os cálculos de gradiente térmico foram usados os valores médios gerais (Figura 12).

As rochas siliciclásticas mostram valores médios de condutividade térmica de 4,085 W/mK. Dentre esses valores, ocorrem distinções entre arenitos e buchitos. Enquanto os
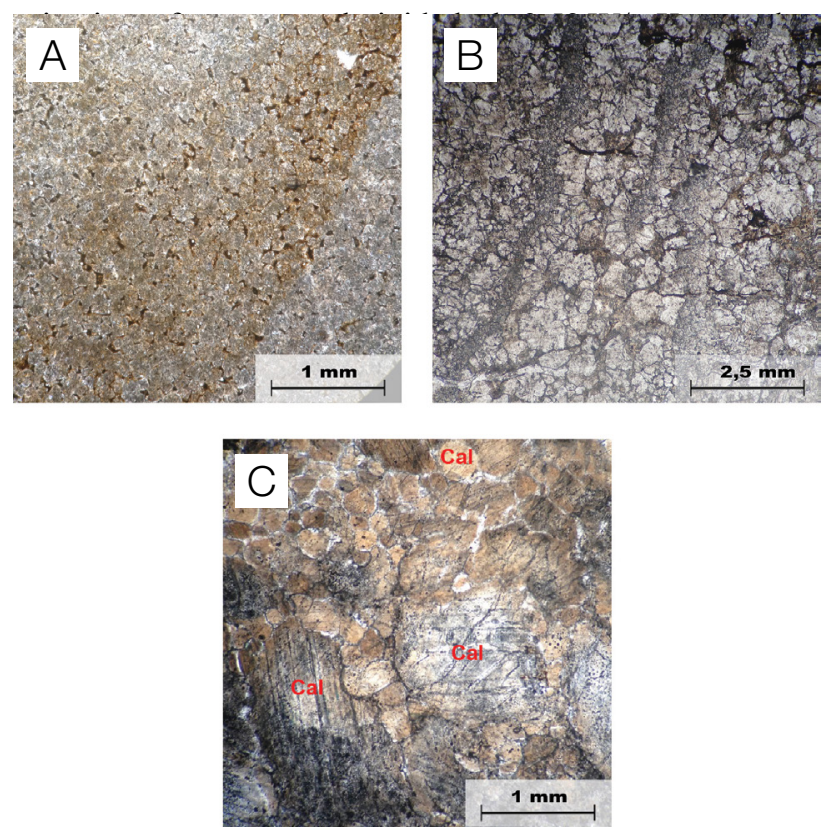

Cal: calcita.

Figura 9. Aspectos das rochas carbonáticas no entorno do plug São João (nicóis paralelos). (A) mudstone pouco afetado com aparente aglutinação por compactação do micrito; (B) calcário muito afetado com fraturas preenchidas por calcita porfiroblástica em textura mosaico poligonal; (C) aspecto microscópico do calcário transformado em mármore com megacristais de calcita e dolomita. Amostras SJ-32, J79-3B e SJ-26, respectivamente.
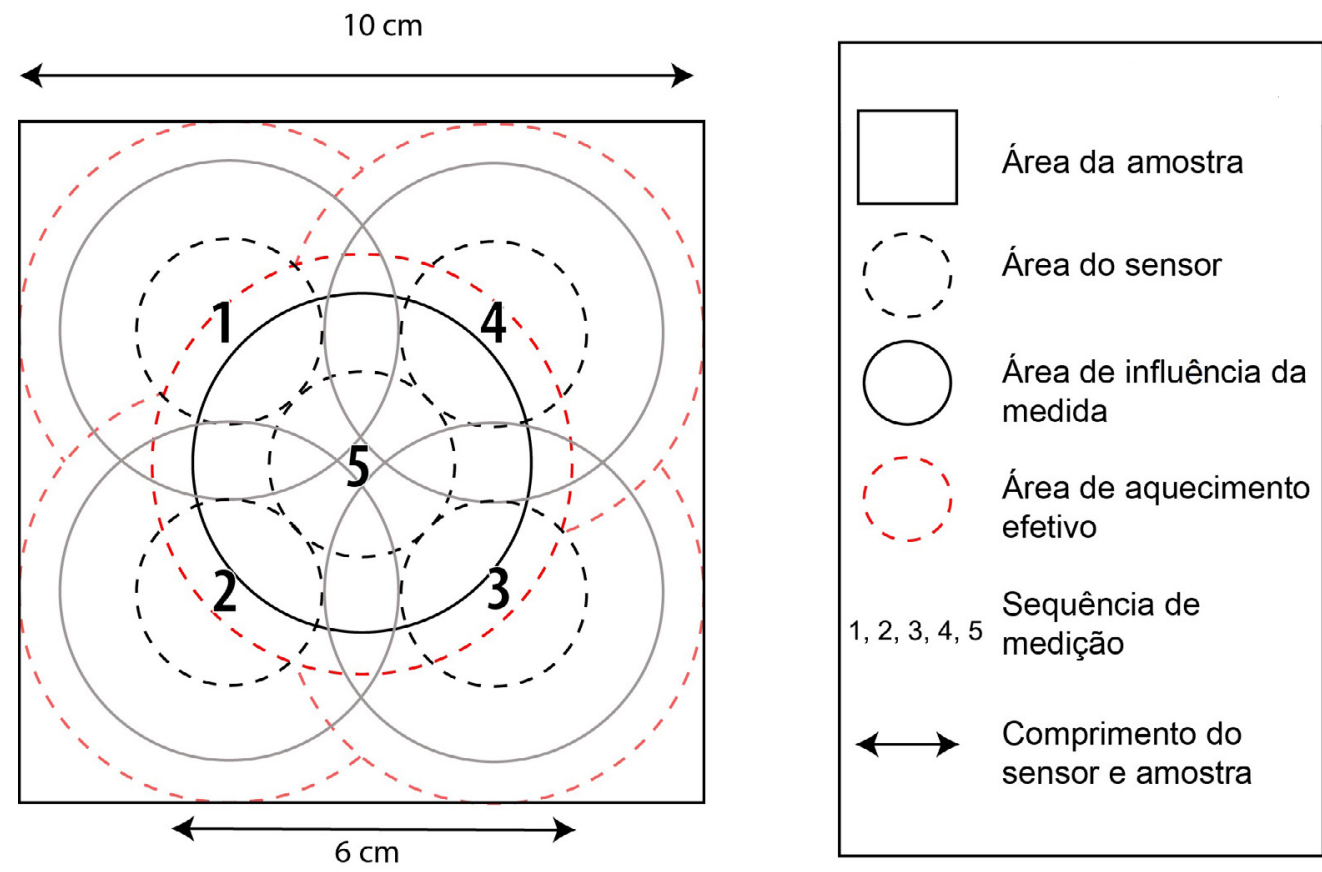

Obs: Espessura constante de $3 \mathrm{~cm}$

Figura 10. Procedimento de aquisição dos dados de difusividade térmica, calor específico e condutividade térmica. 


\begin{tabular}{|c|c|c|}
\hline \multicolumn{3}{|c|}{$\begin{array}{l}\text { Rochas básicas } \\
\text { ( } 25 \text { medições }-5 \text { amostras) }\end{array}$} \\
\hline \multirow{2}{*}{$\lambda(\mathrm{W} / \mathrm{m} . \mathrm{K})$} & Média & 1,83 \\
\hline & Desvio-padrão & 0,027 \\
\hline \multirow{2}{*}{$a\left(m^{2} / s\right)$} & Média & 8,64E-07 \\
\hline & Desvio-padrão & 1,82E-08 \\
\hline
\end{tabular}

\section{Composição de rochas básicas (9 amostras)}

\begin{tabular}{l|l|l|}
\hline Olivina & Média (\%) & Desvio-Padrão (\%) \\
\hline Augita & 6,00 & 5,0 \\
\hline Opacos & 22,00 & 12,0 \\
\hline Plagioclásio & 10,00 & 6,0 \\
\hline Matriz & 53,00 & 9,0 \\
\hline Carbonato & 8,00 & 11,0 \\
\hline Apatita & 1,00 & 3,0 \\
\hline Calcedônia & 0,02 & 0,3 \\
\hline Vidro & 0,01 & 0,4 \\
\hline
\end{tabular}

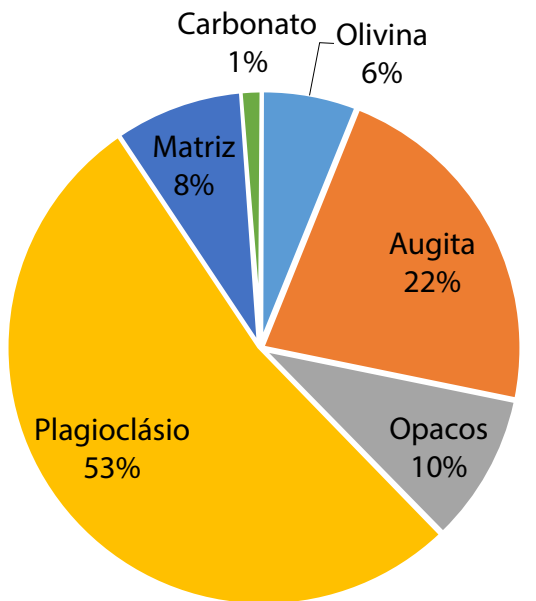

Composição modal média global

$\lambda$ : condutividade térmica; a: difusividade térmica.

Figura 11. Dados estatísticos referentes às médias de condutividade térmica, difusividade térmica e composição mineral das rochas básicas estudadas.

\begin{tabular}{|c|c|c|}
\hline \multicolumn{3}{|c|}{$\begin{array}{l}\text { Rochas carbonáticas } \\
\text { (15 medições }-3 \text { amostras) }\end{array}$} \\
\hline \multirow[b]{2}{*}{$\lambda(\mathrm{W} / \mathrm{m} . \mathrm{K})$} & Média & 3,16 \\
\hline & Desvio padrão & 0,441 \\
\hline \multirow{2}{*}{$a\left(m^{2} / s\right)$} & Média & 1,41E-06 \\
\hline & Desvio padrão & 1,1E-07 \\
\hline
\end{tabular}

\begin{tabular}{|l|l|l|}
\hline \multicolumn{3}{|c|}{ Composição de rochas carbonáticas (9 amostras) } \\
\hline & Média (\%) & Desvio Padrão (\%) \\
\hline Bioclasto & 4,0 & 6,0 \\
\hline Intraclasto & 2,0 & 5,0 \\
\hline Micrito & 24,0 & 30,0 \\
\hline Dolomita & 38,0 & 32,0 \\
\hline Calcita & 25,0 & 29,0 \\
\hline Opacos & 3,0 & 3,0 \\
\hline Terrigenos & 3,0 & 2,0 \\
\hline Porosidade & 0,9 & 1,9 \\
\hline
\end{tabular}

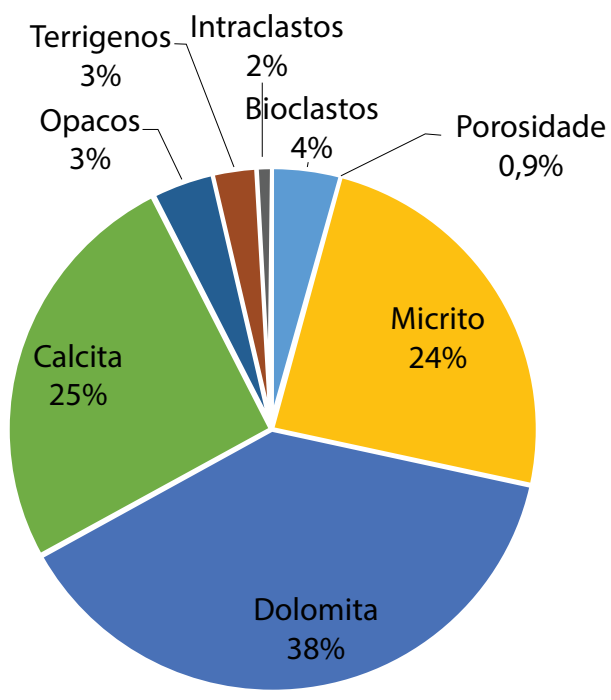

\section{Composição modal média global}

$\Lambda$ : condutividade térmica; a: difusividade térmica.

Figura 12. Dados estatísticos sobre as médias de condutividade térmica, difusividade térmica e composição mineral das rochas carbonáticas estudadas. 
é decorrente dos efeitos de compactação. Em termos quantitativos, nota-se diminuição de porosidade de 9 para $3 \%$, observada em lâminas delgadas, em um intervalo de $20 \mathrm{~m}$ de distância entre as amostras.

Os buchitos analisados apresentam vidro devitrificado (formado no processo de pirometamorfismo), porosidade inexistente e cimento preservado constituído por calcedônia. Embora tenham menor quantidade de quartzo, a ausência de porosidade garante maior condutividade aos buchitos em relação aos arenitos observados. A Figura 13 ilustra a composição e as medições médias encontradas nas rochas siliciclásticas analisadas.

\begin{tabular}{|c|c|c|}
\hline \multicolumn{3}{|c|}{$\begin{array}{l}\text { Arenito Ferruginoso } \\
\text { ( } 5 \text { medições }-1 \text { amostra) }\end{array}$} \\
\hline \multirow{2}{*}{$\Lambda(W / m . K)$} & Média & 3,53 \\
\hline & Desvio-padrão & 0,149 \\
\hline \multirow[b]{2}{*}{$a\left(m^{2} / s\right)$} & Média & 1,81E-06 \\
\hline & Desvio-padrão & 6,83E-08 \\
\hline \multicolumn{3}{|c|}{$\begin{array}{l}\text { Buchito Claro } \\
\text { (10 medições }-2 \text { amostra) }\end{array}$} \\
\hline \multirow{2}{*}{$\lambda(\mathrm{W} / \mathrm{m} . \mathrm{K})$} & Média & 4,36 \\
\hline & Desvio-padrão & 0,124 \\
\hline \multirow{2}{*}{$a\left(\mathrm{~m}^{2} / \mathrm{s}\right)$} & Média & 1,86E-06 \\
\hline & Desvio-padrão & $4,52 \mathrm{E}-08$ \\
\hline
\end{tabular}

\begin{tabular}{|l|l|l|}
\hline \multicolumn{3}{|l|}{ Composição de buchitos (3 amostras) } \\
\hline Quartzo & 41,0 & 36,0 \\
\hline K-Feldspato & 3,0 & 2,0 \\
\hline $\begin{array}{l}\text { Intraclasto } \\
\text { argiloso }\end{array}$ & 3,0 & 2,0 \\
\hline Opacos & 1,0 & 1,0 \\
\hline Hidróxidos & 1,0 & 1,0 \\
\hline Calcedônia & 8,0 & 7,0 \\
\hline Carbonato & 0,3 & 0,6 \\
\hline Plagioclásio & 2,0 & 2,0 \\
\hline Porosidade & 0,0 & 0,0 \\
\hline Vidro & 23,0 & 27,0 \\
\hline Cordierita & 15,0 & 26,0 \\
\hline
\end{tabular}

Sobre as densidades das rochas, percebe-se que os calcários termicamente afetados pela intrusão apresentam valores de $2,95 \mathrm{~g} / \mathrm{cm}^{3}$, o que é maior do que as médias de $2,50 \mathrm{a}$ $2,70 \mathrm{~g} / \mathrm{cm}^{3}$ encontradas na literatura (Horai, 1971) para calcários não afetados. Esse aumento está possivelmente ligado aos efeitos de compactação por recristalização apresentados nas rochas da região. Para os arenitos ferruginosos, os valores de densidade superam aqueles encontrados nos buchitos, o que poderia estar relacionado à presença de cimento ferruginoso no arenito avaliado. Já os arenitos arcoseanos não afetados têm densidade próxima à encontrada na literatura, assim como os diabásios (Figura 14).

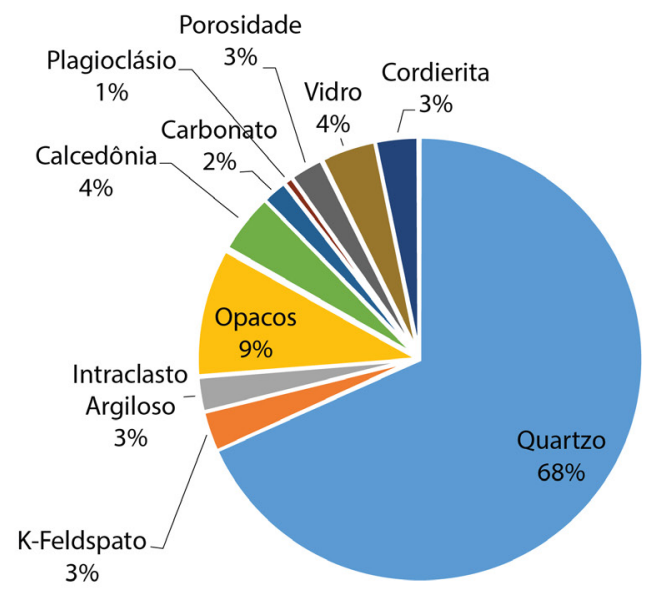

Composição modal média global

\begin{tabular}{|l|l|l|}
\hline \multicolumn{3}{|l|}{ Composição de arenitos (13 amostras) } \\
\hline Quartzo & 73,0 & Desvio-padrão (\%) \\
\hline K-Feldspato & 3,0 & 10,0 \\
\hline $\begin{array}{l}\text { Intraclasto } \\
\text { argiloso }\end{array}$ & 3,0 & 2,0 \\
\hline Opacos & 10,0 & 4,0 \\
\hline Hidróxidos & 0,0 & 9,0 \\
\hline Calcedônia & 5,0 & 0,0 \\
\hline Carbonato & 2,0 & 7,0 \\
\hline Plagioclásio & 1,0 & 3,0 \\
\hline Porosidade & 3,0 & 1,0 \\
\hline Vidro & 0,0 & 6,0 \\
\hline Cordierita & 0,0 & 0,0 \\
\hline
\end{tabular}

$\lambda$ : condutividade térmica; a: difusividade térmica.

Figura 13. Dados estatísticos sobre as médias de condutividade térmica, difusividade térmica e mineralogia das rochas siliciclásticas estudadas. 
De acordo com Jaeger (1964), é possível gerar perfis tempo versus temperatura e distância versus temperatura utilizando um modelo matemático de fluxo de calor, que prevê a extensão aproximada do efeito térmico e o tempo de aporte de calor. Além disso, quando associado a dados de petrografia, é possível observar como o calor produz mudanças nas rochas encaixantes a diferentes distâncias da intrusão. Embora as equações propostas pelo autor sejam baseadas em geometrias intrusivas simples (por exemplo: esfera, cilindro, paralelepípedo etc.), o perfil de temperatura para o plug São João pode ser estimado por se tratar de um corpo aproximadamente esférico, com base em sua exposição superficial relativamente circular, e comprovado por evidências geofísicas gravimétricas (Damaceno et al., 2017). Para esse tipo de modelo, os erros que podem estar associados aos cálculos matemáticos de fluxo de calor consistem nas seguintes simplificações (Jaeger, 1968, apud Esposito e Whitney, 1995):

- a condutividade e a difusividade para a encaixante e a intrusão são consideradas homogêneas dentro de cada tipo litológico;

- as intrusões ocorreram instantaneamente em termos geológicos, assumindo a ausência de pré-aquecimento da encaixante;

- a energia de cristalização de alguns minerais é negligenciada neste modelo, porém, neste caso, os erros inerentes a essa simplificação podem ser corrigidos com o aumento do valor de temperatura da fonte térmica (para fins de cálculo);

- as propriedades térmicas de ambas as unidades, sedimentares e ígneas, são consideradas independentes umas das outras; $\mathrm{e}$

- efeitos convectivos associados não são considerados.

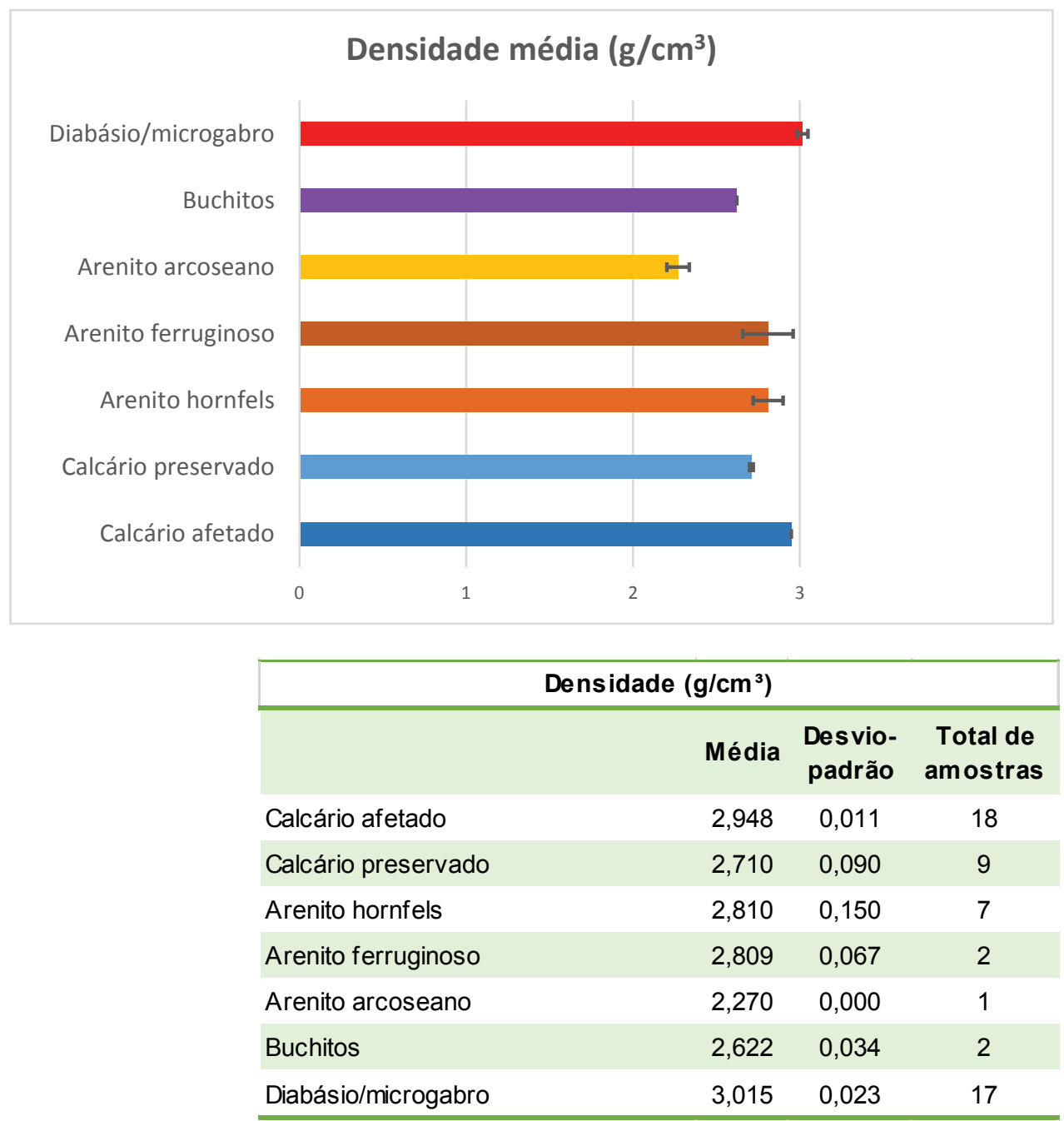

Figura 14. Dados de densidade dos diversos litotipos presentes na região e o desvio-padrão encontrado. Compilados de Sousa (2009) e Damaceno et al. (2017). 
O último aspecto pode introduzir os maiores erros, embora os efeitos da temperatura sobre a difusividade e a condutividade ainda sejam pouco compreendidos (Esposito e Whitney, 1995). A importância de vários fatores complicadores foi avaliada por Jaeger (1964), que concluiu que os erros relativos a essas premissas surtem efeito apenas sobre avaliações do perfil de temperatura no interior da intrusão. Fora da intrusão, as equações gerais se mantêm com uma acurácia relativamente boa.

De acordo com Jaeger (1964), os parâmetros espessura, tempo pós-colocação, distância da intrusão e propriedades térmicas de encaixantes (difusividade e condutividade) podem ser expressos em dois parâmetros adimensionais $\varepsilon$ e $\tau$ (Lovering, 1935). A Tabela 1 sumariza as relações matemáticas utilizadas no cálculo proposto pelo autor e define os parâmetros usados no modelamento térmico.

Para simplificar os cálculos de resfriamento, Jaeger (1964) expressou a integral tripla de aquecimento por difusão na forma unidimensional:

$T=T_{0} \theta(\varepsilon, \tau)$

Para corpos esféricos, utiliza-se:

$$
\begin{aligned}
& \theta(\varepsilon, \tau)=\frac{1}{2}\left\{\operatorname{erf}\left(\frac{\varepsilon+1}{2 \tau^{1 / 2}}\right)-\operatorname{erf}\left(\frac{\varepsilon-1}{2 \tau^{1 / 2}}\right)-\frac{2 \tau^{1 / 2}}{\varepsilon \tau^{1 / 2}}\right. \\
& \left.\left[\exp \left[-\frac{(\varepsilon-1)^{2}}{4 \tau}\right]-\exp \left[-\frac{(\varepsilon+1)^{2}}{4 \tau}\right]\right]\right\}
\end{aligned}
$$

As equações (1) e (2) podem ser combinadas para calcular a temperatura em uma distância especificada de um corpo esférico intrusivo:

Tabela 1. Relações matemáticas para o cálculo do fluxo térmico.

$\mathrm{T}$ Temperatura, dependente do tempo, em um dado ponto

$T_{0}$ Temperatura inicial do magma

d Raio da intrusão

$\mathrm{d}_{1}$ Eixo menor de um corpo intrusivo cilíndrico

$\mathrm{d}_{2}$ Eixo maior de um corpo intrusivo cilíndrico

Difusividade termal da rocha encaixante. Valores

a obtidos em laboratório

t Tempo decorrido desde a intrusão

Equivalente adimensional para qualquer tempo, onde:

$\tau \quad \tau=\frac{a \cdot t}{d^{2}} ; \tau_{1}=\frac{a \cdot t}{d_{1}^{2}} ; \tau_{2}=\frac{a \cdot t}{d_{2}^{2}}$

x Distância da intrusão

Equivalente adimensional para qualquer distância da intrusão, onde:

$\varepsilon=\frac{x}{d} ; \varepsilon_{1}=\frac{x}{d_{1}} ; \varepsilon_{2}=\frac{(1-x)}{d_{2}}$

I Distância entre duas intrusões
$\frac{T}{T_{0}}=\frac{1}{2}\left\{\operatorname{erf}\left(\frac{\varepsilon+1}{2 \tau^{1 / 2}}\right)-\operatorname{erf}\left(\frac{\varepsilon-1}{2 \tau^{1 / 2}}\right)-\frac{2 \tau^{1 / 2}}{\varepsilon \tau^{1 / 2}}\right.$

$\left.\left[\exp \left[-\frac{(\varepsilon-1)^{2}}{4 \tau}\right]-\exp \left[-\frac{(\varepsilon+1)^{2}}{4 \tau}\right]\right]\right\}$

Para locais com sobreposição das ondas de calor providas pelas intrusões é necessário combinar os efeitos das duas fontes caloríferas, logo:

$\frac{T}{T_{0}}=\theta\left(\varepsilon_{1}, \tau_{1}\right)+\theta\left(\varepsilon_{2}, \tau_{3}\right)$

Onde:

$\left(\varepsilon_{1}, \tau_{1}\right)=$ parâmetros adimensionais do primeiro corpo; $\mathrm{e}$

$\left(\varepsilon_{2}, \tau_{3}\right)=$ parâmetros adimensionais para o segundo corpo.

Dessa forma, passa-se a admitir o valor 1 assim:

$\varepsilon_{2}=\frac{(1-x)}{d_{2}^{2}}$

As fórmulas (4) e (5) não foram utilizadas devido à escassez de dados sobre o corpo adjacente. Além disso, para os locais de estudo, não houve características que marcassem influência expressiva da segunda fonte de calor, tornando a simulação válida quando considerado apenas um corpo.

O perfil temperatura versus distância e tempo foi calculado usando os valores estimados ou medidos da Tabela 2 . Com isso, pôde-se obter o gradiente térmico do plug no decorrer do tempo.

Os cálculos foram realizados pelo software Maple 2016.1a (build 1133417). A unidade de tempo usada foi o ano, representada por intervalos logarítmicos $(1,10,100,1.000$ e 10.000) no perfil temperatura versus distância. Como o modelo matemático assume um único valor de difusividade para as encaixantes, utilizou-se a média entre esses valores para os arenitos e os calcários. A Figura 15 mostra as curvas de temperatura calculadas segundo as premissas mencionadas anteriormente.

\begin{tabular}{|c|c|c|}
\hline Variável & Valor & Fonte \\
\hline Difusividade $(\alpha)$ & $\begin{array}{c}53,17 \mathrm{~m}^{2} / \mathrm{ano} \\
\left(1,69 \times 10^{-6} \mathrm{~m}^{2} / \mathrm{s}\right)\end{array}$ & Medida em laboratório \\
\hline $\begin{array}{l}\text { Temperatura } \\
\text { inicial }\left(T_{0}\right)\end{array}$ & $1.200^{\circ} \mathrm{C}$ & $\begin{array}{l}\text { Temperatura do } \\
\text { liquidus de um magma } \\
\text { toleiítico, associações } \\
\text { pirometamórficas da } \\
\text { área e em regiões } \\
\text { próximas (Santos et al., } \\
\text { 2014; Terra et al., 2016) }\end{array}$ \\
\hline $\begin{array}{l}\text { Raio da } \\
\text { intrusão (d) }\end{array}$ & $350 \sim 500 \mathrm{~m}$ & $\begin{array}{l}\text { Controle de campo e } \\
\text { sensoriamento remoto }\end{array}$ \\
\hline
\end{tabular}

Tabela 2. Valores usados para os cálculos de fluxo térmico. 


\section{DISCUSSÃO}

As intrusões na região do plug São João afetaram localmente as rochas encaixantes de forma heterogênea. As siliciclásticas e carbonáticas sofreram a influência do calor gerado pelas intrusões básicas, resultando em auréolas metamórficas com intensidades variadas.

A ocorrência de calcários silicificados e minerais carbonáticos (calcita e dolomita) em geodos e fraturas nas porções interiores da intrusão implica em mobilidade de cálcio, magnésio e sílica, pelo menos em pequenas distâncias (em torno de 0 a $15 \mathrm{~m}$ da intrusão). Esses íons podem ter sido trazidos pela liberação de fluidos durante a intrusão ou pela dissolução de grãos nas rochas encaixantes. No caso da primeira hipótese, Ferry e Dipple (1991) discutem que o fluxo convectivo causado por esse processo pode redistribuir calor para a rocha encaixante. Logo, além da condução, o fluxo convectivo aumenta localmente a temperatura do sistema. Todavia, o aumento de temperatura em questão é irrisório comparado à taxa de transferência condutiva "regional", restringindo-se basicamente ao contato ígneosedimentar, fato que pode gerar inconsistências no modelamento matemático utilizado nas regiões, já que o cálculo é direcionado a fluxos puramente condutivos. Porém, é algo que pode ser facilmente retificado com dados petrográficos e mineralógicos.

Nos calcários micríticos, é notável a melhora de sua "cristalinidade" em decorrência do aumento da temperatura. Esse fenômeno pode ser explicado pela recristalização de dolomita e calcita na matriz, formando pequenos cristais. A variação da temperatura provoca, nesses cristais, maior taxa de recristalização, aumentando, consequentemente, a granulometria da rocha. Em algumas regiões da auréola metamórfica notam-se metacalcários dolomíticos com textura cristalina grossa e cristais atingindo 5 a $8 \mathrm{~mm}$. É possível que, antes de gerar os mármores calcíticos encontrados

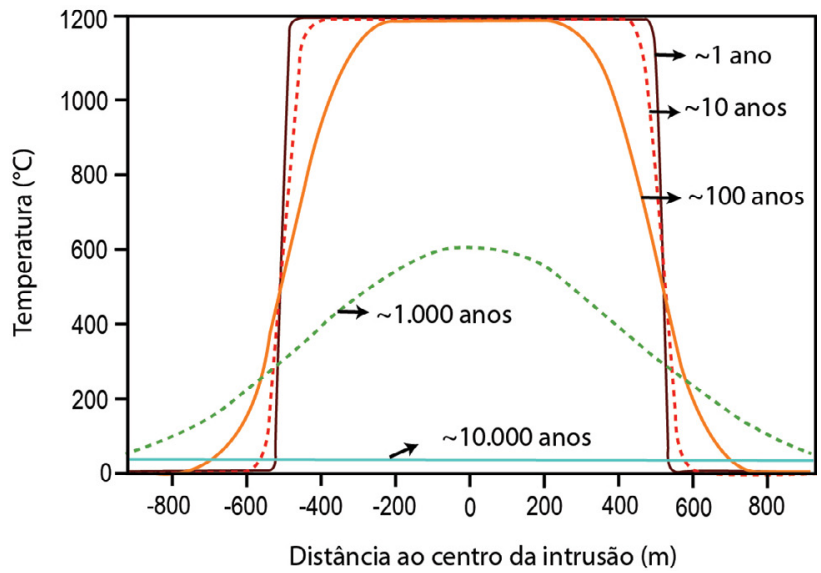

Figura 15. Perfil de fluxo térmico do entorno do corpo ígneo principal do plug São João. como xenólitos do plug básico, os dolomitos tenham passado pelo processo de desdolomitização, gerando, novamente, calcita. Porém, isso não foi observado nas lâminas descritas.

Por meio da análise dos dados petrográficos, foi possível supor que, próximo ao contato (ou em xenólitos), as rochas encaixantes alcançam $850{ }^{\circ} \mathrm{C} \sim 1.100{ }^{\circ} \mathrm{C}$ (Grapes, 2011), formando associações minerais características como cordierita e vidro a partir de rochas parcialmente fundidas (buchitos). Nota-se que, em maior parte, trata-se de rochas englobadas pelo corpo básico (xenólitos), com pressões inferiores a 0,5 kbar. Além disso, é possível inferir elevada taxa de arrefecimento, identificada no material vítreo devitrificado e pelo tamanho reduzido dos minerais de cordierita gerados nesse tipo de rocha.

Em lugares próximos à área de estudo, as temperaturas das rochas encaixantes perto dos contatos intrusivos variam de 1.100 a $1.250^{\circ} \mathrm{C}$, com pressões de até $1 \mathrm{kbar}$. Essas localidades foram interpretadas por análises de assembleias minerais em microssonda eletrônica e microscópio eletrônico de varredura, com caracterização de cordierita, tridimita, clinoenstatita e espurrita (Santos et al., 2014; Terra, 2015; Terra et al., 2016).

De acordo com a análise petrográfica integrada ao mapeamento geológico de detalhe, que aproximou o alcance do pirometamorfismo à intrusão, nota-se que o seu campo de atuação restringe-se a $5 \mathrm{~m}$ do contato.

Com base nos modelos matemáticos de fluxo térmico propostos por Jaeger (1964), as condições de temperatura proximais ao entorno das intrusões são inconsistentes devido ao advento do fluxo convectivo, embora para regiões distais o modelo permaneça coerente. Logo, ao se integrar esse modelo com dados petrográficos, foi possível construir um mapa de alcance térmico e zonas metamórficas capaz de estimar o comportamento térmico no entorno das intrusões com boa acurácia. Nesse procedimento, nota-se que as mudanças petrofísicas e petrográficas ocorrem nos calcários a partir de $400{ }^{\circ} \mathrm{C}$, até $150 \mathrm{~m}$ do corpo avaliado. Mudanças para rochas moderadamente afetadas iniciam-se em $550{ }^{\circ} \mathrm{C}$, enquanto as muito afetadas sofrem mudanças texturais e mineralógicas com temperaturas a partir de $1.000{ }^{\circ} \mathrm{C}$ (Figuras 16A e 17).

Comparando-se os dados de modelamento térmico 1D e a zona de efeito pirometamórfico, verifica-se uma pequena região a sudoeste do corpo que foge dos padrões de temperaturas correlacionados aos efeitos metamórficos observados (Figura 16A). Dados gravimétricos sugerem que, nessa região anômala, uma provável extensão do corpo ígneo seja encontrada em profundidade (Figura 16B). Logo, esse fato poderia implicar no fornecimento mais acentuado de calor para as rochas na região, o que é desconsiderado no modelamento realizado, já que existe a limitação de trabalhar apenas com geometrias simples. Todavia, fora da área em questão, os dados se mantêm coerentes. 


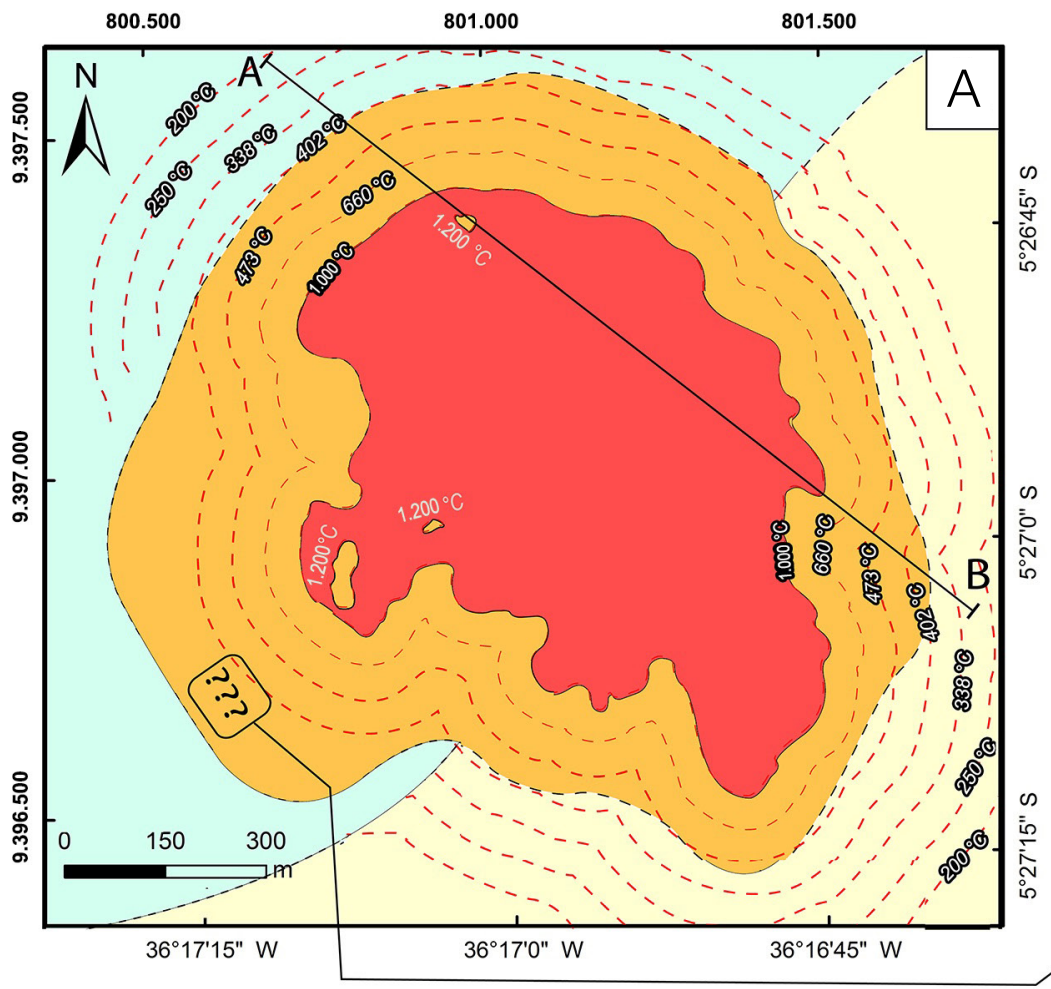

\section{Unidades geológicas Auréola metamórfica Magmatismo Macau Formação Jandaíra Formação Açu}

\section{Convenções cartográficas}

Isolinhas de temperatura $\left(T_{\max }\right)$

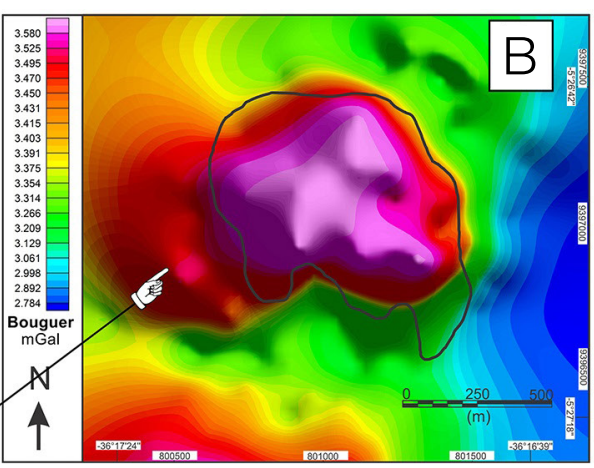

Figura 16. (A) Modelamento térmico integrado; (B) possível explicação para divergências nos dados de isoterma e efeitos pirometamórficos na porção sudoeste, representada pela possível extensão do corpo esférico em profundidade, observável em gravimetria, fornecendo calor local não previsto em modelamento. Mapa gravimétrico compilado de Damaceno et al. (2017).

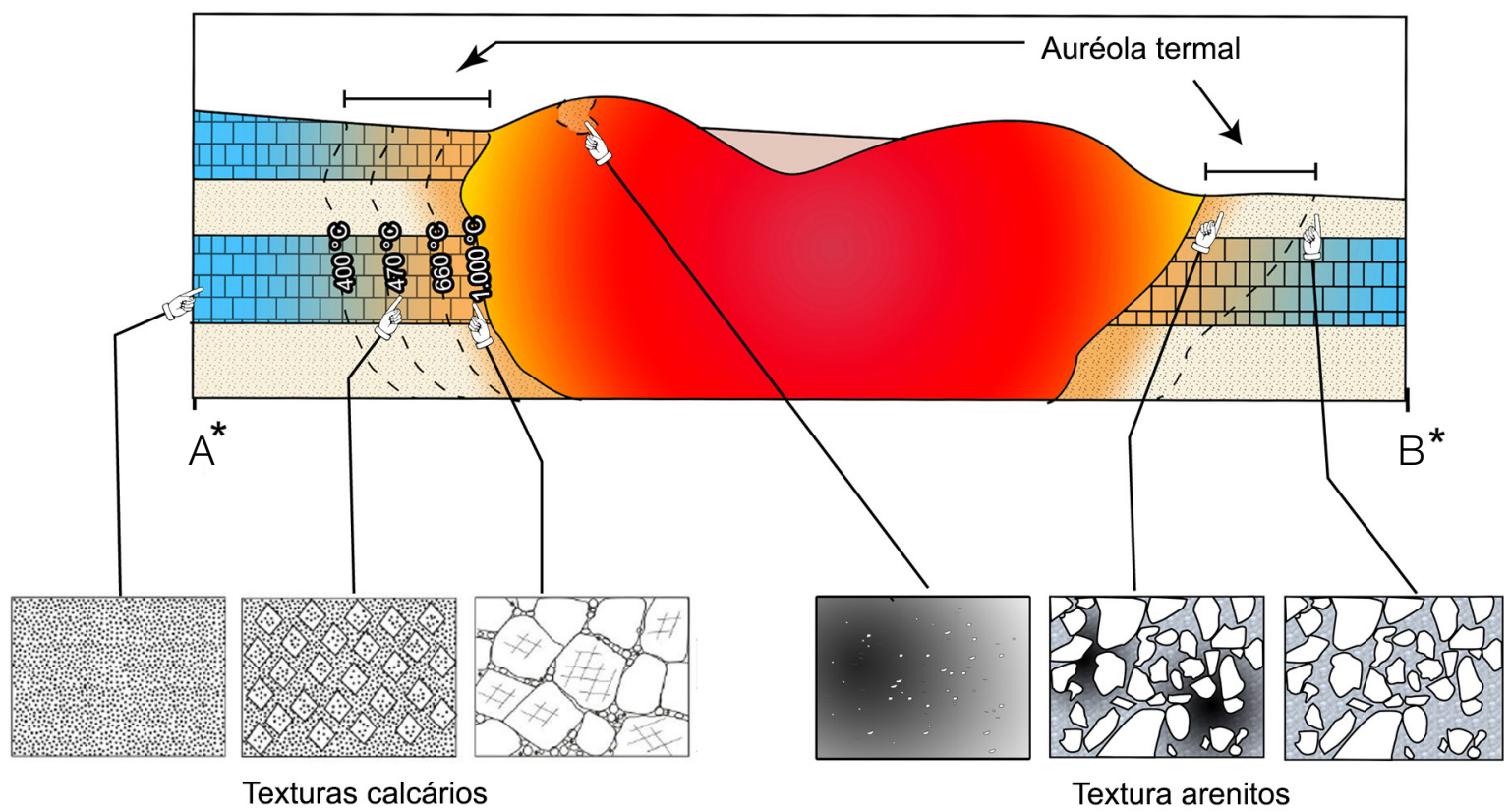

Figura 17. Relação entre o modelamento térmico e texturas de calcários (adaptado de Terra, 2015) e arenitos termicamente afetados e não afetados (perfil A-B da Figura 16A). 
Já em arenitos, as principais mudanças ocorrem em temperaturas acima de $850^{\circ} \mathrm{C}$, presente em xenólitos no corpo ígneo ou próximo ao contato. Além dessas distâncias, o fornecimento de calor não é suficiente para provocar mudanças mineralógicas e texturais nas rochas no entorno das intrusões. Nesse caso, fora da auréola metamórfica, onde não há destruição de matéria orgânica, a energia térmica poderia propiciar a catalisação do seu processo de maturação, além de outros fatores benéficos à indústria petrolífera. Todavia, modelamentos térmicos quantitativos mais detalhados devem ser realizados na Bacia Potiguar, envolvendo principalmente os análogos de rochas-fontes e/ou dados em poços próximos de intrusões para, assim, haver melhor entendimento desse fenômeno.

\section{CONCLUSÕES}

Os dados apresentados permitem listar as conclusões a seguir:

- o plug São João é um corpo intrusivo hipoabissal composto por diabásio e microgabro, da borda para o centro, com geometria aproximadamente esférica e que, possivelmente, estende-se em profundidade na sua borda sudoeste;

- os protólitos das rochas encaixantes afetadas são arenitos ferruginosos, subarcoseanos e quartzo-arenitos da Formação Açu e calcários dolomíticos e calcíticos (dos tipos mudstone, wackestone e grainstone) da Formação Jandaíra;

- por meio do modelamento térmico, integrado a feições petrográficas e texturais, é possível estimar as condições de $\mathrm{P}-\mathrm{T}$ mínimas $\left(850 \mathrm{a} 1.000^{\circ} \mathrm{Ce} 0,5 \mathrm{kbar}\right.$ ) para a formação de algumas rochas encontradas nos contatos ígneos-sedimentares;

- rochas pirometamórficas são geradas devido ao calor do corpo do plug São João em até $5 \mathrm{~m}$ a partir do contato. Todavia, modificações na rocha encaixante ocorrem até $150 \mathrm{~m}$ devido aos efeitos termais $\left(\mathrm{T}_{\text {máx }} \sim 400^{\circ} \mathrm{C}\right)$;

- o tempo de fornecimento de calor oriundo do corpo ígneo de São João para as rochas encaixantes foi estimado em aproximadamente 10 mil anos;

- em alguns locais, as condições de sistema aberto permitiram a percolação de fluidos oriundos provavelmente das encaixantes, gerando fraturas preenchidas por materiais carbonáticos ou silicosos; e

- o fluxo térmico nos corpos da região é majoritariamente condutivo, embora fluxos hidrotermais locais possam existir.

\section{AGRADECIMENTOS}

Os autores Samir do Nascimento Valcácio e Zorano Sérgio de Souza agradecem à Coordenação de Aperfeiçoamento de Pessoal de Nível Superior (CAPES) e ao Conselho Nacional de Desenvolvimento e Pesquisa (CNPq) pelas bolsas de Mestrado e Pesquisa (processo 449616/2014-2), respectivamente, assim como ao Programa de Pós-Graduação em Geodinâmica e Geofísica da Universidade Federal do Rio Grande do Norte (PPGG - UFRN), ao Departamento de Geologia (DGeo. UFRN) e ao Departamento de Geofísica (DGeof. - UFRN) pela disponibilização de sua infraestrutura e serviços.

\section{REFERÊNCIAS}

Angelim, L. A. A., Medeiros, V. C., Nesi, J. R. (2006). Mapa geológico do Estado do Rio Grande do Norte. Programa Geologia do Brasil - PGB. Projeto Geologia e Recursos Minerais do Estado do Rio Grande do Norte. Escala 1:500.000. Recife: CPRM/FAPERN.

Araújo, M. G. S., Brito Neves, B. B., Archanjo, C. J. (2001). Idades 40Ar/39Ar do magmatismo básico Meso-Cenozóico da Província Borborema Oriental, nordeste do Brasil. XIX Simpósio de Geologia do Nordeste (260-261). Natal: SBG.

Cassab, R. C. T. (2003). Paleontologia da Formação Jandaíra, Cretáceo Superior da Bacia Potiguar, com ênfase na paleobiologia dos gastrópodos. Tese (Doutorado). Rio de Janeiro: Instituto de Geociências - UFRJ.

Chang, H. K., Kowsmann R. O., Figueiredo A. M. F. (1988). New concepts on the development of East Brazilian Marginal Basins. Episodes, 11, 194-202.

Chen, Z., Yan, H., Li, J., Zhang, G., Zhang, Z., Liu, B. (1999). Relationship between tertiary volcanic rocks and hydrocarbons in the Liaohe Basin, People's Republic of China. American Association of Petroleum Geologists, 83(6), 1004-1014.

Damaceno, J. G., Castro, D. L., Valcacio, S. N., Souza, Z. S. (2017). Magnetic and gravity modeling of a Paleogene diabase plug in Northeast Brazil. Journal of Applied Geophysics, $136,219-230$.

Dunham, R. J. (1962). Classification of carbonate rocks according to deposicional texture. In: W. E. Ham (Ed.). Classification of carbonate rocks (v. 1, 108-121). Tulsa: AAPG Memoir.

Eiras, J. F., Wanderley Filho, J. R. (2003). Sistemas petrolíferos ígneo-sedimentares. $2{ }^{\circ}$ Congresso Brasileiro de $P \& D$ em Petróleo \& Gás (6 p.). Rio de Janeiro: UFRJ.

Esposito, K. J., Whitney, G. (1995). Thermal effects of thin igneous intrusions on diagenetic reactions in a Tertiary basin of southwestern Washington: U.S. Geological Survey Bulletin, 2085-C, C1-C40.

Ferry, J. M., Dipple, G. M. (1991). Fluid flow, mineral reactions, and metasomatism. Geology, 19, 211-214. 
Folk, R. L. (1959). Practical petrographic classification of limestones. Bulletin of the American Association of Petroleum Geologists, 43, 1-38.

Folk, R. L. (1968). Petrology of sedimentary rocks. Austin: Hemphill.

Grapes, R. H. (2011). Pyrometamorphism. $2^{\text {nd }}$ ed. Berlin: Springer.

Horai, K. (1971). Thermal Conductivity of Rock-Forming Minerals. Journal of Geophysics Research, 76(5), 1278-1308.

Jaeger, J. C. (1964). Thermal effects of intrusions. Reviews of Geophysics, 2, 443-466.

Kahn, J. S. (1956). The Analysis and distribution of the properties of packing in sand size sediments: 1 . On the measurement of packing in sandstones. Journal of Geology, 64, 385-395.

Knesel, K. M., Souza, Z. S., Vasconcelos, P. M., Cohen, B. E., Silveira, F. V. (2011). Young volcanism in the Borborema Province, NE Brazil, show no evidence for a trace of Fernando de Noronha plume on the continent. Earth and Planetary Science Letters, 302, 38-50.

Lovering, T. S. (1935). Theory of heat conduction applied to geological problems. Geological Society of America Bulletin, 46, 69-94.

Matos, R. M. D. (1992). The Northeast Brazilian rift system. Tectonics, 11, 766-791.

Matos, R. M. D. (2000). Tectonic evolution of the Equatorial South Atlantic. In: W. U. Mohriak, M. Talwani (Eds.). Atlantic rifts and continental margins. Geophysical Monograph, 115, 331-354. DOI: 10.1029/GM115.

Mizusaki, A. M. P., Thomaz Filho, A., Milani, E.J., Césero, P. (2002). Mesozoic and Cenozoic igneous activity and its tectonic control in northeastern Brazil. Journal of South American Earth Sciences, 15, 183-198.

Nobre, H. A. M. (2012). Petrografia e propriedades petrofísicas de rochas sedimentares da Bacia Potiguar termalmente afetadas por intrusões básicas cenozóicas, Jandairra - RN. Relatório (Graduação). Natal: Curso de Geologia - UFRN.

Paiva, H. S. (2004). Caracterização geológica e petrografia de corpos vulcânicos cenozoicos na região de Lajes a Pedro Avelino-RN. Relatório (Graduação). Natal: Curso de Geologia - UFRN.
Pessoa Neto, O. C., Soares, U. M., Da Silva, J. G. F., Roesner, E. H., Florencio, C. P., Souza, C. A. V. (2007). Bacia Potiguar. Boletim de Geociências da Petrobras, 15(2), 357-369.

Pettijohn, F. J., Potter, P. E., Siever R. (1972). Sand and Sandstones. New York: Springer Verlag.

Pettijohn, F. J., Potter, P. E., Siever R. (1987). Sand and Sandstones. $2^{\text {nd }}$ ed. New York: Springer Verlag.

Santos, L. (2011). Ocorrência de Buchitos na Bacia Potiguar $(R N)$ : implicações na Exploração de Hidrocarbonetos. Relatório (Graduação). Natal: Curso de Geologia - UFRN.

Santos, L. (2013). Pirometamorfismo nos arenitos da Formação Açu, Bacia Potiguar, NE do Brasil. Dissertação (Mestrado). Natal: Pós-Graduação em Geodinâmica e Geofísica - UFRN.

Santos, L., Souza, Z. S., Botelho, N. F., Viana, R. R. (2014). Pirometamorfismo ígneo na Bacia Potiguar, Nordeste do Brasil. Geologia USP. Série Científica, 14, 121-138.

Schmidt, V., Mcdonald, D. A. (1979). Texture and recognition of secondary porosity in sandstones. In: P. A. Scholle, P. R. Schluger (Eds.). Aspects diagenesis (26,209-225). Society of Economic Paleontologists and Mineralogists.

Scholle, P. A. (1979). A Color Illustrated Guide to Constituents, Textures, Cements, and Porosities of Sandstones and Associated Rocks: Tulsa, OK. American Association of Petroleum Geologists, 28, 200-201.

Silveira, F. V. (2006). Magmatismo cenozóico da porção central do Rio Grande do Norte, NE do Brasil. Tese (Doutorado). Natal: Programa de Pós-Graduação em Geodinâmica e Geofísica - UFRN.

Sousa, V. F. C. (2009). Efeitos térmicos provocados por intrusões básicas cenozóicas em rochas cretácicas da Bacia Potiguar na região de Pedro Avelino (RN). Relatório (Graduação). Natal: Curso de Geologia - UFRN.

Souza, Z. S., Santos, L., Botelho, N. P. (2012). Igneous pyrometamorphism: Implications for hydrocarbon exploration in NE Brazil. XXXIV International Geological Congress (2949). Brisbane: University of Queensland.

Souza, Z. S., Vasconcelos, P. M., Knesel, K. M., Dias, L. G. S., Roesner, E. H., Farias, P. R. C., Morais Neto, J. M. (2013). The tectonic evolution of Cenozoic extensional basins, northeast Brazil: Geochronological constraints from continental basalt ${ }^{40} \mathrm{Ar}{ }^{39} \mathrm{Ar}$ ages. Journal of South American Earth Sciences, 48, 159-172. 
Souza, Z. S., Vasconcelos, P. M. P., Nascimento, M. A. L., Silveira, F. V., Paiva, H. S.; Dias, L. G. S.; Thied, D.; Carmo, I. O. (2003). ${ }^{40} \mathrm{Ar} /{ }^{39} \mathrm{Ar}$ geochronology of Mesozoic and Cenozoic magmatism in NE Brazil. 4th South American Symposium on Isotope Geology, Short Papers (2, 691-694). Salvador: CPGeo e Instituto de Geociências da USP.

Souza, Z. S., Vasconcelos, P. M. P., Silveira, F. V. (2007). Vulcanismo no NE do Brasil: reavaliação da Formação Macau. XXII Simpósio de Geologia do Nordeste $(20,189)$. Natal: SBG.

Streckeisen, A. (1976). To each plutonic rock its proper name. Earth Science Reviews, 12(1), 1-33.

Terra, S. A. (2015). Pirometamorfismo em calcários da Formação Jandaíra, Bacia Potiguar, NE do Brasil. Dissertação (Mestrado). Natal: Programa de Pós-Graduação em Geodinâmica e Geofísica - UFRN.

Terra, S. A., Souza, Z. S., Botelho, N. F., Viana, R. R., Legrand, J. M., Srivastava, N. K. (2016). Pirometamorfismo em carbonatos cretácicos da Formação Jandaíra, Bacia
Potiguar, Nordeste do Brasil. Geologia USP. Série Cientifica, $16,61-83$.

Thomaz Filho, A., Mizusaki, A. M. P., Antonioli, L. (2008). Magmatismo nas bacias sedimentares brasileiras e sua influência na geologia do petróleo. Revista Brasileira de Geociências, 38(2, supl. 1), 128-137.

Ujié, Y. (1986). Contact-metamorphic effect on parameters for kerogen maturation. Organic Geochemistry, 9(6), 375-378.

Vital, H., Tabosa, W. F., Farias, P. R. C., Souza, Z. S., Lima, Z. M. C., Araújo, P. C., Silva, D. R. V. (2011). Carta Geológica Folha Jandaíra SB.24-X-D-III. Programa Geologia do Brasil. Escala 1:100.000. CPRM/UFRN.

Wang, D., Zhao, M., Qi, T. (2012). Heat-Transfer-Model Analysis of the Thermal Effect of Intrusive Sills on OrganicRich Host Rocks in Sedimentary Basins. In: Dar, I. A. (Ed.). Earth Sciences (91-98). Croatia: InTech.

Wentworth, C. K. (1922). A Scale of Grade and Class Terms for Clastic Sediments. The Journal of Geology, 30(5), 377-392. 